\title{
A PRODUÇÃO DE VÍDEOS NA FORMAÇÃO INICIAL DE PROFESSORES EM DIDÁTICA DA MATEMÁTICA
}

\author{
LA PRODUCCIÓN DE VÍDEOS EN LA FORMACIÓN INICIAL DE \\ PROFESORES EN DIDÁTICA DE LA MATEMÁTICA
}

\section{THE PRODUCTION OF VIDEOS IN PRESERVICE TACHER EDUCATION IN DIDATICS OF MATHEMATICS}

\author{
Maria Eliza Brefere ARNONI ${ }^{1}$ \\ Ricardo SCUCUGLIA ${ }^{2}$
}

\begin{abstract}
RESUMO: Neste artigo apresentamos um estudo de caso qualitativo para discutir a criação de vídeos digitais na formação inicial de professores de matemática. O cenário de produção audiovisual é a disciplina Didática da Matemática e a principal temática de discussão dos estudantes é a atividade educativa, com ênfase na Metodologia da Mediação Dialética (M.M.D.). Os estudantes de graduação optaram por uma estrutura narrativa composta por três momentos: (1) exibição textual com fundo musical sobre as fases da atividade educativa e as etapas da M.M.D. (2) apresentação de uma performance musical criada sobre a M.M.D. (3) depoimentos dialógicos/reflexivos dos estudantes sobre o papel didático-pedagógico da M.M.D. na formação e atuação dos professores. Em nossa análise, destacamos o uso das artes e da multimodalidade no processo formativo dos três futuros professores de matemática na narrativa digital produzida. Consideramos que o vídeo criado apresenta aspectos pertinentes no que se refere ao sentido conceitual, emoção e sensação e que o uso de tecnologias digitais voltadas para a produção audiovisual tem grande potencial na prática docente formativa. E, neste aspecto, torna-se relevante explicitar que o processo educativo centrado na M.M.D. é desenvolvido na formação dos licenciandos e, por eles, na formação conceitual dos alunos da escola básica.
\end{abstract}

PALAVRAS-ChAVE: Vídeos digitais. Metodologia da mediação dialética.

Multimodalidade.

RESUMEN: En este artículo presentamos un estudio de caso cualitativo para discutir la creación de videos digitales en la formación inicial de profesores de matemáticas. El escenario de producción audiovisual es la disciplina Didáctica de la Matemática y la principal temática de discusión de los estudiantes es la actividad educativa, con énfasis en la Metodología de la Mediación Dialéctica (M.M.D.). Los estudiantes de licenciatura han optado por una estructura narrativa compuesta de tres partes: (1) visualización textual con música de fondo en las etapas de la actividad educativa y los pasos de M.M.D. (2) presentación de una performance musical creada sobre la M.M.D.

1 Universidade Estadual Paulista (Unesp), São José do rio Preto - SP - Brasil. Professora do Departamento de Educação do Instituto de Biociências. E-mail: meliza @ibilce.unesp.br.

${ }^{2}$ Universidade Estadual Paulista (Unesp), São José do rio Preto - SP - Brasil. Professor do Departamento de Educação do Instituto de Biociências. E-mail: ricardos@ibilce.unesp.br.

RPGE- Revista on line de Política e Gestão Educacional, Araraquara, v.21, n.esp.3, p. 1575-1587, dez., 2017. 
(3) testimonios dialógicos / reflexivos de los estudiantes sobre el papel didácticopedagógico de la M.M.D. En la formación y actuación de los profesores. en nuestro análisis, destacamos el uso del arte y de la multimodalidad en el proceso formativo de los tres futuros profesores de matemáticas en la narrativa digital producida. Consideramos que el video creado presenta aspectos pertinentes en lo que se refiere al sentido conceptual, emoción y sensación y que el uso de tecnologías digitales dirigidas a la producción audiovisual tiene un gran potencial innovador en la práctica docente formativa. En este aspecto, resulta relevante aclarar que el proceso educativo centrado en la M.M.D. se desarrolla en la formación de los licenciandos y, por ellos, en la formación conceptual de los alumnos de la escuela básica.

PALABRAS-CLAVE: Vídeos digitales. Metodología de la mediación dialéctica. Multimodalidad.

ABSTRACT: In this article, we present a qualitative case study to discuss the creation of digital videos in pre-service mathematics teacher education. The audiovisual production scenario is a course of Didactics of Mathematics and the main subject of students' discussion is the educational activity, with emphasis on the Methodology of Dialectic Mediation (M.M.D.). Undergraduate students created a narrative structure composed of three moments: (1) textual display with musical background on the phases of the educational activity and the stages of M.M.D. (2) presentation of a musical performance created on M.M.D. (3) dialogic / reflective discussion of students about the didactic-pedagogical role of M.M.D. in training and performance of teachers. In our analysis, we highlight the use of the arts and multimodality in the formative process of the three future teachers of mathematics in the digital narrative produced. We believe that the video created has pertinent aspects regarding conceptual sense, emotion and sensation and that the use of digital technologies has great innovative potential in teaching practice. In this respect, it becomes relevant to highlight that the educational process centered on M.M.D. is developed in the education of undergraduate students, regarding the conceptual formation of students of the elementary school.

KEYWORDS: Digital videos. Methodology of Dialectic Mediation. Multimodality.

\section{Introdução}

O uso de tecnologias digitais (portáteis) com acesso à Internet tem se tornado uma atividade social de grande expressão, a qual inclui a produção e publicação online de vídeos. No entanto, uma atividade desse tipo pode ser considerada um evento raro em ambientes educacionais. De maneira geral, as práticas em salas de aula não refletem a realidade tecnológica cotidiana de muitos estudantes e professores. Os motivos para tal dicotomia envolvem aspectos que perpassam por questões de infraestrutura, políticas públicas e manutenção de tradições didático-pedagógicas na formação de professores. Em nossas práticas enquanto docentes em um curso de Licenciatura em

RPGE- Revista on line de Política e Gestão Educacional, Araraquara, v.21, n.esp.3, p. 1575-1587, dez., 2017. 
Matemática, temos buscado fomentar a produção audiovisual como atividade formativa de futuros professores (SCUCUGLIA, 2014). Neste artigo, especificamente, apresentamos um estudo de caso qualitativo para discutir tais questões.

A produção de vídeos digitais enquanto prática formativa em cursos de licenciatura (em matemática) é parte significativa de nossa atividade docente. De acordo com Borba, Scucuglia e Gadanidis (2014) o uso de tecnologias digitais na formação inicial de professores de matemática oferece meios para se explorar a multimodalidade. Tradicionalmente, a atividade matemática comunicacional e avaliativa de estudantes e professores está fundamentada prioritariamente no uso da linguagem escrita e suas mídias (lápis e papel, por exemplo). Com o advento da linguagem informática e o uso de mídias digitais, esses agentes podem estar imersos em um cenário semiótico investigativo pautado na utilização de diversos modos de comunicação e representação. A produção de vídeos, por exemplo, compila diversos tipos de vocabulários, imagens, sons, gestos e outras modalidades (WALSH, 2011).

A criação de narrativas digitais multimodais (SCUCUGLIA, 2014), além de abarcar uma dimensão artística-performática (cinema), implica em demandas diferenciadas em termos de processos formativos/aprendizagem decorrente da referida complexidade semiótica. Além disso, é um processo peculiar de construção de identidade (BRUNER, 1996) e uma prática alternativa na formação inicial de professores de matemática (GADANIDIS; BORBA, 2008).

Para Arnoni (2014), o professor, ao entender a aula como práxis social, entende também que é possível transformá-la e, apresenta a proposição teórico-metodológica da atividade educativa, uma práxis social fundamentada na ontologia do ser social (MARX, 2006; LUKÁCS, 1979), como possibilidade de superar o modelo burguês de aula determinado pelos manuais didáticos oficiais.

A atividade educativa compõe-se de três fases distintas que se articulam num processo educativo desenvolvido pelo professor: $\mathbf{1}^{\mathbf{a}}$ Fase - desenvolvimento conceitual e intelectual do professor, pelo estudo dos referenciais teóricos que embasam sua ação docente; $2^{\mathbf{a}}$ Fase - planejamento, desenvolvimento e avaliação da prática educativa, via M.M.D. $3^{\mathbf{a}}$ Fase - avaliação plena da atividade educativa.

A efetividade desta proposição centra-se na avaliação processual que permite o professor e os alunos desenvolverem sequencialmente a articulação entre as fases da atividade educativa e as etapas da M.M.D., em que, os dados da análise das produções de uma fase ou de uma etapa são os elementos para o planejamento da seguinte, visando 
a aprendizagem conceitual do aluno. Um dos recursos avaliativos é a produção do vídeo livre com tema aberto em Didática da Matemática. Neste artigo, analisamos um desses vídeos, produzidos por três licenciandos, em 2014.

\section{Metodologia}

Nossas práticas docentes envolvem a produção de vídeos enquanto proposta pedagógica no curso de Licenciatura em Matemática da Universidade Estadual Paulista, Campus de São José do Rio Preto, SP. Ao longo do último triênio (2013-2016), diversos de nossos estudantes produziram vídeos nos âmbitos das disciplinas Estágio Supervisionado e Didática da Matemática. Tais vídeos estão baseados em duas temáticas principais: (1) Performance Matemática Digital (SCUCUGLIA, 2012) e (2) Tema Livre em Didática da Matemática. Tais produções são parte de atividades de pesquisas, com objetivos pautados em questionamentos que podem ser enunciados da seguinte maneira: Como a produção de performances matemáticas digitais fomenta a construção de imagens alternativas sobre a matemática? Como a produção de vídeos digitais pode contribuir com a formação de professores em Didática da Matemática? Quais os papéis metodológicos dessas produções digitais?

Neste artigo, optamos por uma abordagem metodológica fundamentada no estudo de caso qualitativo (STAKE, 2000). Ou seja, analisamos um vídeo produzido por três estudantes na disciplina Didática da Matemática em 2014, o qual envolve aspectos educacionais que consideramos relevantes no contexto da produção audiovisual na formação inicial de professores como a formação digital (multimodalidade), a criação artística e a reflexão teórico-prática. Neste caso, a práxis como atividade educativa, uma ação formativa, fundamentada na M.M.D. (ARNONI, 2014).

O vídeo analisado, intitulado "Didática da Matemática - A Metodologia da Mediação Dialética" tem duração de $6 \mathrm{~m} 41 \mathrm{~s}$ e foi produzido por três licenciandos em Matemática, os quais utilizaram câmera digital integrada a telefone celular e editor de vídeos Microsoft MovieMaker. Considerado a própria estrutura narrativa do vídeo produzido pelos alunos, optamos em apresentar nossa análise em três seções.

\section{A atividade educativa, a Metodologia da Mediação Dialética e a Didática da Matemática}

RPGE- Revista on line de Política e Gestão Educacional, Araraquara, v.21, n.esp.3, p. 1575-1587, dez., 2017. 
Na disciplina Didática da Matemática (ARNONI, 2011), o licenciando vivencia a atividade educativa em duas dimensões distintas e intimamente relacionadas: a) Como aluno, busca aprender processualmente a concepção de atividade educativa, vivenciando a M.M.D.; b) Como licenciando-docente, vivencia a docência ao operacionalizar a atividade educativa com alunos da Escola Básica, há uma experiência única, complexa e efetiva, ao se desenvolver o conceito matemático com seus alunos, pautando-se nos mesmos princípios filosóficos que orientaram o desenvolvimento dos conceitos da Didática e, consequentemente sua aprendizagem conceitual, assistida pela avaliação processual.

A primeira parte do vídeo, com duração de aproximadamente $1 \mathrm{~m} 20 \mathrm{~s}$, apresenta de forma textual as 3 (três) fases da atividade educativa, enfatizando as ações que as caracterizam, exibindo imagens (fotos) de uma atividade educativa de matemática, desenvolvida pelos licenciandos em uma sala de aula de uma turma dos anos finais do Ensino Fundamental, na qual desenvolveram o conceito de Arcos e Ângulos, com base na M.M.D. A seguir, apresentamos uma sequência de imagens capturadas do vídeo digital produzido pelos estudantes.

Figura 1: Cenas iniciais do vídeo
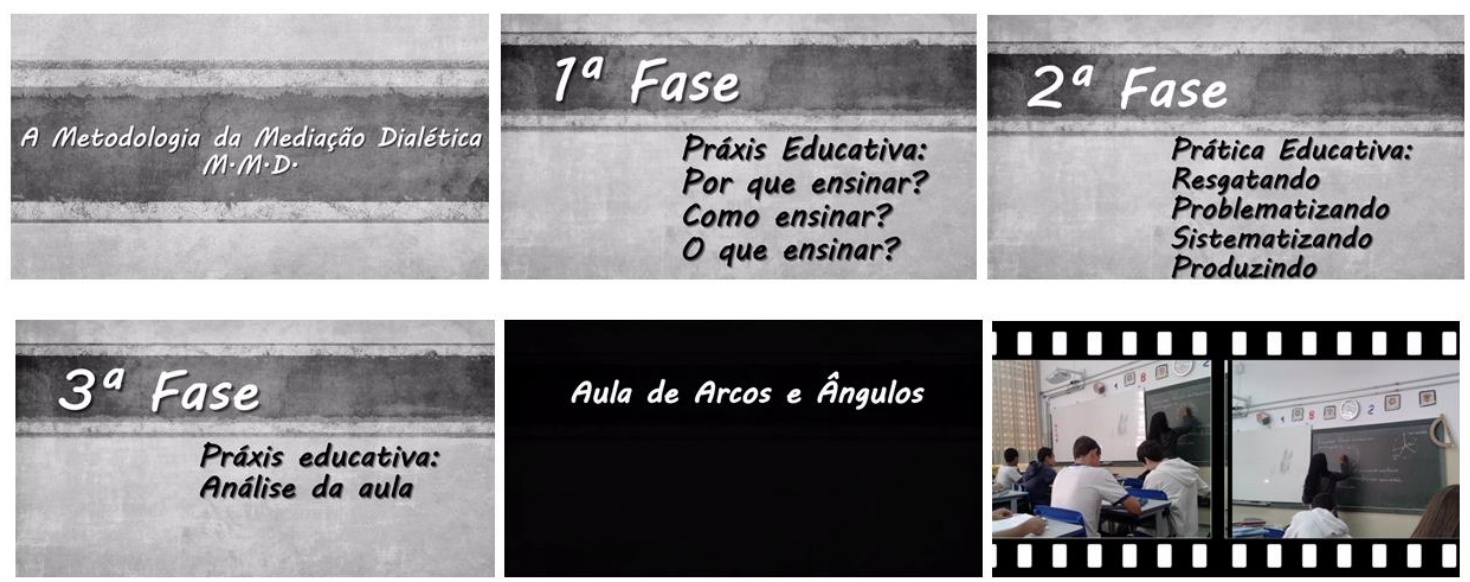

Fonte: Dados de pesquisa

O vídeo explora a dimensão teórico-prática de cada uma das fases da atividade educativa, como práxis educativa: - estudar os fundamentos ontológicos para planejar a atividade educativa $\left[1^{\mathrm{a}}\right.$ Fase $]$; - aplicar os fundamentos para organizar metodologicamente o conceito matemático, desenvolvê-lo com os alunos, via M.M.D. e analisar a aprendizagem conceitual do aluno na prática educativa [ $2^{\mathrm{a}}$ Fase]; - avaliar a atividade educativa, em sua totalidade [ $3^{\mathrm{a}}$ Fase].

RPGE- Revista on line de Política e Gestão Educacional, Araraquara, v.21, n.esp.3, p. 1575-1587, dez., 2017. 
Do ponto de vista da produção audiovisual educacional, o vídeo apresenta aspectos interessantes em termos de conceituais (SCUCUGLIA, 2012). Além do sentido conceitual (conteúdo pedagógico), a produção dos estudantes envolve nuances referentes a emoções e sensações (forma). A trilha sonora oferece a audiência um prazer vicário. Por sua vez, a imersão/atividade em sala de aula revela uma experiência direta, visceral. De acordo com Boorstin (1990), esses são aspectos que caracterizam um bom filme.

\section{A música "Ciclo sem fim..."}

Na segunda parte do vídeo, o qual tem duração de aproximadamente $2 \mathrm{~m} 50 \mathrm{~s}$, os estudantes apresentam uma performance musical. De maneira criativa, eles elaboraram uma letra e conduziram uma paródia da canção popularmente conhecida como "O Rei Leão". A esquerda da imagem do vídeo, os alunos exibiram a letra da música. Ao lado direito, exibiram uma performance, cantando e mostrando cartazes com termos-chave que explicavam conceitos inerentes à práxis educativa e à M.M.D., de maneira sincronizada, ou seja, conforme a música fazia menção aos conceitos, os cartazes eram exibidos de modo a enfatizar as expressões fundamentais.

No quadro 1 apresentamos a letra da música criada pelos estudantes e na Figura 2, uma sequência de imagens capturadas do vídeo.

Quadro 1: Letra da música

Ciclo Sem Fim (Paródia de O Rei Leão)

Desde o dia em que a escola chegamos

Coletando as ideias iniciais

Pela contradição

Buscando a emancipação

E é este a caminho a seguir Usando os nexos para conseguir

Problematizar e sistematizar

Para enfim o aluno produzir

É o ciclo sem fim

Que nos guiará

Pela mediação

'A superação

Até encontrar

O nosso caminho

Neste ciclo, neste ciclo sem fim

Fonte: dados de pesquisa

RPGE- Revista on line de Política e Gestão Educacional, Araraquara, v.21, n.esp.3, p. 1575-1587, dez., 2017. 
Figura 2: Cenas da performance musical

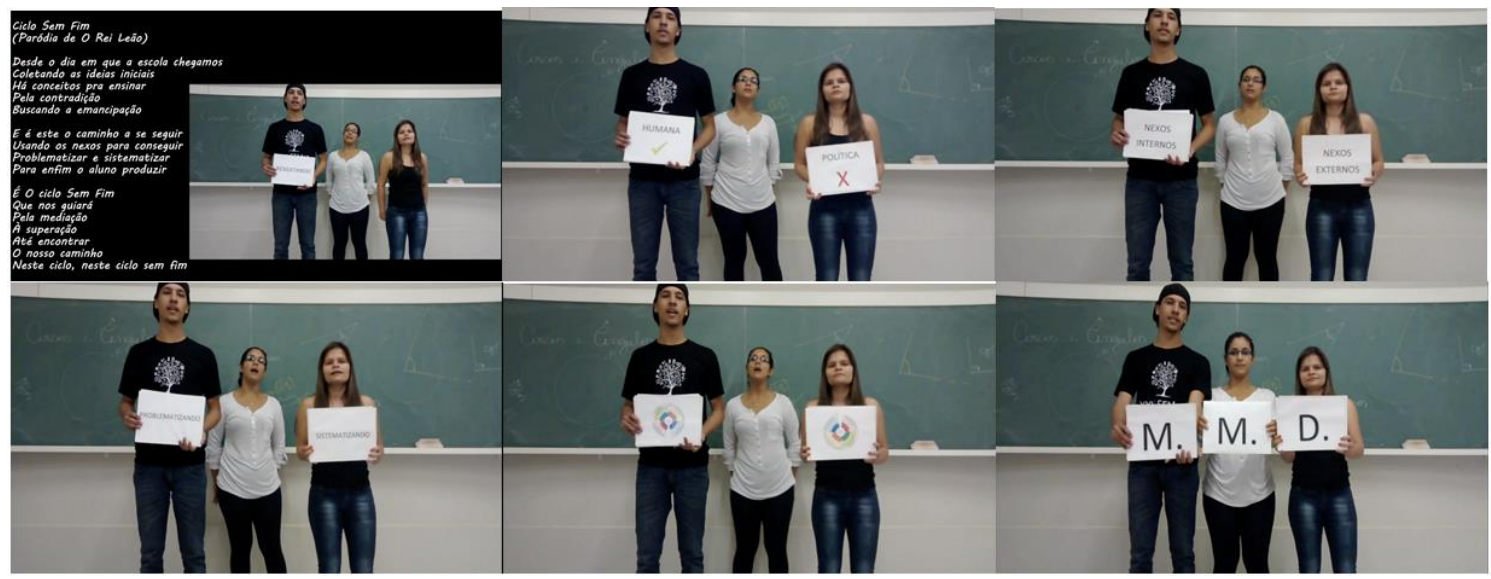

Fonte: Dados de pesquisa

Ao analisarmos o vídeo, notamos que a expressão "coletando ideias iniciais" é associada ao termo "Resgatando" do cartaz; a frase "buscando a emancipação" é associada aos termos "humana" e "política"; "usando nexos para conseguir" é associada a "nexos internos" e "nexos externos" do conceito ensinado; os termos "Sistematizar", "Problematizar" e "Produzir" são citados no gerúndio, indicando movimento do pensamento, em sua ação de pensar. Finalmente, de maneira criativa, os alunos relacionam a frase "é o ciclo sem fim", refrão original da música "O Rei Leão", à espiral que representa as etapas da M.M.D.

O vídeo refere-se simultaneamente à vivência teórico-metodológica da M.M.D., como alunos da Didática da Matemática e como licenciandos-docentes da Escola Básica. Como alunos, relatam a vivência da M.M.D., em que, resgataram suas ideias iniciais sobre o modelo atual de aula, problematizaram ao estabelecer sua comparação com concepção de atividade educativa, depreenderam a contradição entre ambas e sitematizaram, ao optar conscientemente pela atividade educativa, como possibilidade de superação da aula burguesa, sendo esta opção consciente, a intencionalidade da $1^{\text {a }}$ Fase da atividade educativa, como narram na primeira estrofe. Para isto, como alunos da Didática, estudaram e discutiram a intencionalidade da atividade educativa, a partir das categorias emancipação humana e emancipação política (TONET, 2007) que explicitam os modos de organização das sociedades, no que se refere à produção material e cultural e sua distribuição para as classes sociais. A primeira categoria visa uma formação humana integral, em que o ser social frui dos bens produzidos historicamente pelo homem, em sociedade, e a segunda, expressa a organização da sociedade capitalista, em que o sistema educacional atua na sua manutenção, sendo,

RPGE- Revista on line de Política e Gestão Educacional, Araraquara, v.21, n.esp.3, p. 1575-1587, dez., 2017. 
assim, impossível de se implantar um sistema educacional emancipador e, sim, um sistema educacional pautado na emancipação política, visando à exploração da classe desfavorecida.

Diante desta contradição, a atividade educativa com a intencionalidade de colaborar na formação conceitual e intelectual do professor e do aluno, perspectivando a emancipação humana, apresenta-se como a possibilidade de superação do atual modelo burguês de aula, daí a opção consciente por ela, o que explica a frase da música "Buscando a emancipação" e os termos da $2^{a}$ imagem (Figura 2) - humana e política -, em que foi assinalada a opção pela emancipação humana. E, como licenciandodocentes, reafirmam a opção pela atividade educativa para o desenvolvimento do conceito matemático “Arcos e ângulos" na Escola Básica, como mostra a $1^{\mathrm{a}}$ frase da $2^{\mathrm{a}}$ estrofe "E é este o caminho a seguir". E, para esta proposição, consideram de fundamental importância, o estudo do conceito científico na perspectiva da totalidade, investigando seus nexos internos (conceitos interiores que formam o conceito a ser ensinado) e os nexos externos (conceitos e fatos que se relacionam com o conceito a ser ensinado), como assevera a $2^{\mathrm{a}}$ frase da $2^{\mathrm{a}}$ estrofe "Usando os nexos para conseguir" e a $3^{\text {a }}$ imagem (Figura 2), pelos termos nexos internos e nexos externos, tidos como relevantes para a compreensão das "falas" dos alunos, em relação ao conceito ensinado, bem como, para elaborar as questões sobre o conceito matemático, pautado na categoria dialética que informa cada etapa da M.M.D., como apontam a $3^{\mathrm{a}}$ e a $4^{\mathrm{a}}$ frases da $2^{\mathrm{a}}$ estrofe "Problematizar e sistematizar / Para enfim o aluno produzir" e a $5^{\text {a }}$ imagem (Figura 2), em que apresentam o diagrama da M.M.D., em espiral (ARNONI, 2014).

Com muita propriedade, relacionam a belíssima expressão "ciclo Sem fim” com a sigla M.M.D., expressando o movimento em espiral, gerado pelo processo subjetivo da aprendizagem desenvolvida pelo aluno, ao participar efetivamente das etapas da M.M.D., postas objetivamente e intencionalmente pelo professor, de forma a empoderar o aluno: tomar consciência das ideias iniciais que tem sobre o conceito que está sendo ensinado (Resgatando - totalidade e movimento - contradição entre parte\&parte e parte\&todo); reconhecer a contradição entre suas ideias iniciais e o conceito ensinado (Problematizando - contradição); elaborar o conceito científico (Sistematizando - superação e síntese) e expor sua síntese conceitual (Produzindo exposição da síntese conceitual). Neste processo, a síntese apresenta-se mais elaborada que as ideias iniciais e, esta diferença conceitual impede que o ciclo formado pelas etapas articuladas da M.M.D. se feche, ao contrário, ele permanece aberto e contínuo, 
criando o movimento em espiral infinita que expressa o movimento do pensamento "O Ciclo sem fim...".

Um aspecto essencial da atividade educativa é a mediação, presente na $3^{\mathrm{a}}$ linha da $3^{\text {a }}$ estrofe da música, uma categoria dialética pautada na contradição que congrega as demais categorias como movimento, totalidade, superação, momento predominante, síntese, objetividade e subjetividade. A mediação é uma relação pedagógica pautada na contradição, que o professor estabelece com o aluno, via linguagem, a qual veicula o conhecimento entre ambos, no decorrer do desenvolvimento do conceito educativo com o aluno na prática educativa, via M.M.D.

Neste processo, o aluno, ao vivenciar sequencialmente as etapas metodológicas, desenvolve-se psicointelectualmente por processos distintos e simultâneos da contradição presente na mediação, em que ela - a contradição, "resolve-se e se realiza" pelo momento predominante, sem sofrer superação, ora é o professor que predomina a mediação e, ora, o aluno e, novamente, o professor, num movimento contínuo que direciona o desenvolvimento operacional da M.M.D.

E, no pensamento do aluno, a contradição entre suas ideias e o conceito ensinado pelo professor, está presente em todas as etapas da M.M.D. e, se desenvolve pela superação. Disto, resulta a aprendizagem conceitual do aluno, pois, a cada etapa metodológica, a contradição da mediação, atua no processo de superação das ideias iniciais, visando à elaboração do conceito científico ensinado, criando a espiral contínua e infinita, o ciclo sem fim.

\section{As Vozes dos Estudantes}

$\mathrm{Na}$ terceira parte do vídeo, com duração de aproximadamente $2 \mathrm{~m} 50 \mathrm{~s}$, os estudantes apresentaram de maneira narrativa-oral algumas reflexões sobre a M.M.D.:

Carlos Roberto Lopes Vicente: O interessante dessa metodologia, é que para a gente pra ensinar um conceito, precisa antes verificar se os alunos têm os elementos necessários para aprender esses conceitos, já internalizados.

Amanda Monteiro: O quê, para mim, chamou mais a atenção, é que quando a gente começou o semestre a gente pensava que todo esse processo, todas essas etapas seriam feitas a cada duas ou três aulas, ou, pensando no semestre ou bimestre. Mas, esse processo da espiral pode ser feito em momentos da aula. Por exemplo, se meu aluno perguntar algo, em minha resposta eu vou formular essa espiral para que ele possa entender o que eu estou falando. Então, essa espiral, esse movimento, vai ser feito diversas vezes na aula. Mesmo um

RPGE- Revista on line de Política e Gestão Educacional, Araraquara, v.21, n.esp.3, p. 1575-1587, dez., 2017. 
aluno, para ele pensar em um conceito novo que ele esteja aprendendo, ele vai fazer essa espiral.

Jéssica Aparecida da Silva: E estudando essa metodologia com mais profundidade, eu vejo hoje, que o desenvolvimento do conceito com o aluno é uma coisa mais complexa do que eu via antes. A sala toda pode aprender um conceito, em sua totalidade.

Amanda: A gente estava acostumada a ver aula como algo que a gente tira do livro didático e não fornecer ao aluno os conhecimentos que a gente aprende aqui na faculdade. Então, os nexos internos a gente passou a pesquisar através do conceito que a gente aprende aqui dentro, e não simplesmente tirar de um livro didático.

Após suas falas, antes de exibir os créditos do vídeo, os estudantes apresentaram com maior clareza a espiral que caracteriza a M.M.D. realizando movimento rotacional (Figura 3), explicitando a complexidade e continuidade das 4 etapas.

Figura 3: Espiral da M.M.D.

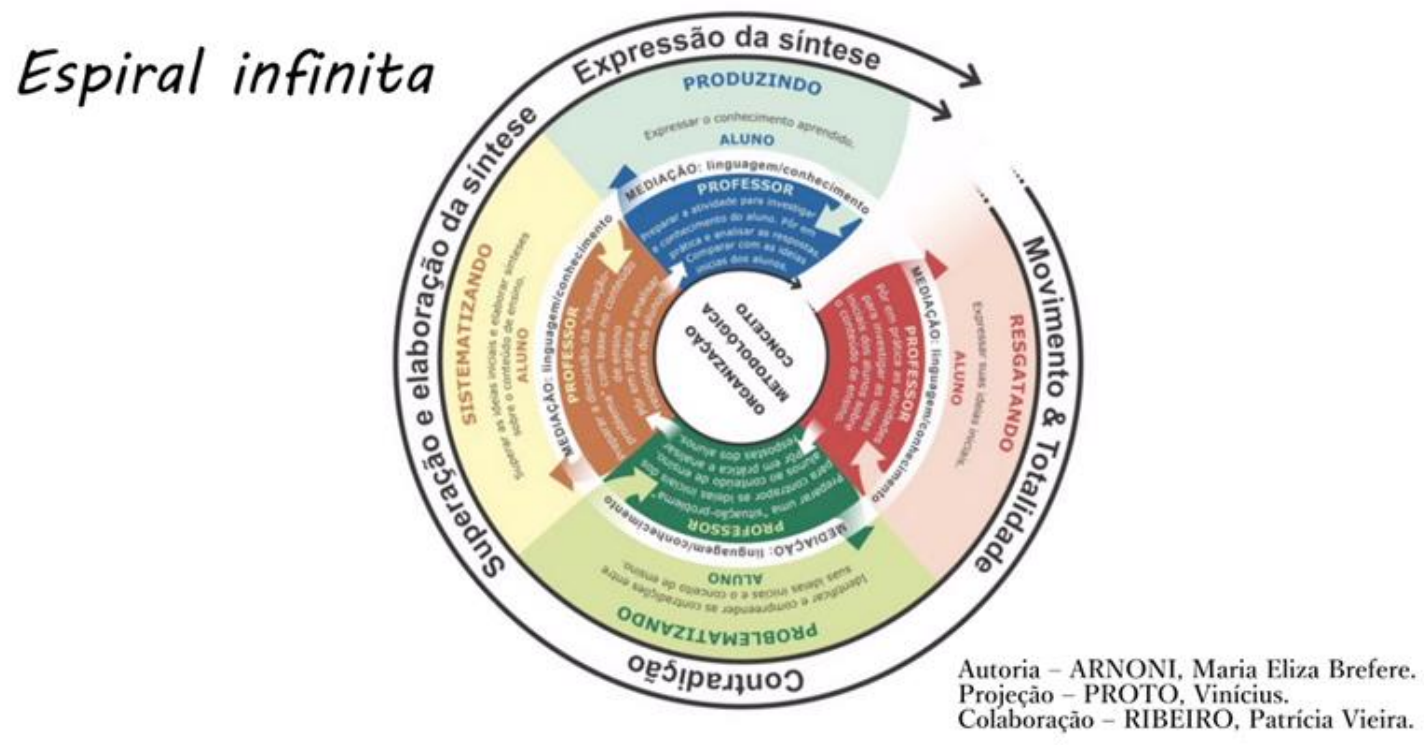

Fonte: dados de pesquisa

\section{Considerações finais}

O uso de tecnologias digitais voltadas a produção audiovisual assume um caráter potencialmente alternativo a formação inicial de professores (de matemática). O estudo de caso apresentado ilustrou como o processo de aprendizagem em Didática da Matemática esteve caracterizado pelo usufruto da multimodalidade (WALSH, 2011), incluindo o uso de expressões artísticas, as quais fomentam a criatividade. Por meio da linguagem escrita, sons, imagens, músicas, gestos, espacialidades e outros modos de comunicação, alunos de um curso de Licenciatura em Matemática puderam explorar de

RPGE- Revista on line de Política e Gestão Educacional, Araraquara, v.21, n.esp.3, p. 1575-1587, dez., 2017. 
maneira reflexiva os fundamentos ontológicos da atividade educativa que se operacionalizam na proposição teórica e metodológica da M.M.D., o momento em que o ser social pode aprender o conceito científico, a unidade do conhecimento que atua no desenvolvimento de suas estruturas psicointelectuais, ampliando suas potencialidades de conhecer e agir conscientemente em vivência, tornando a atividade educativa um processo precípuo que perspectiva a emancipação humana.

Atualmente, buscamos elaborar representações mais aprimoradas sobre a espiral da M.M.D. Na Figura 4 apresentamos algumas dessas representações, as quais utilizaremos nas edições futuras da disciplina Didática da Matemática. Dessa forma, estudantes poderão explorá-las em futuros vídeos digitais produzidos na disciplina.

Figura 4: Representações tridimensionais da espiral na M.M.D.
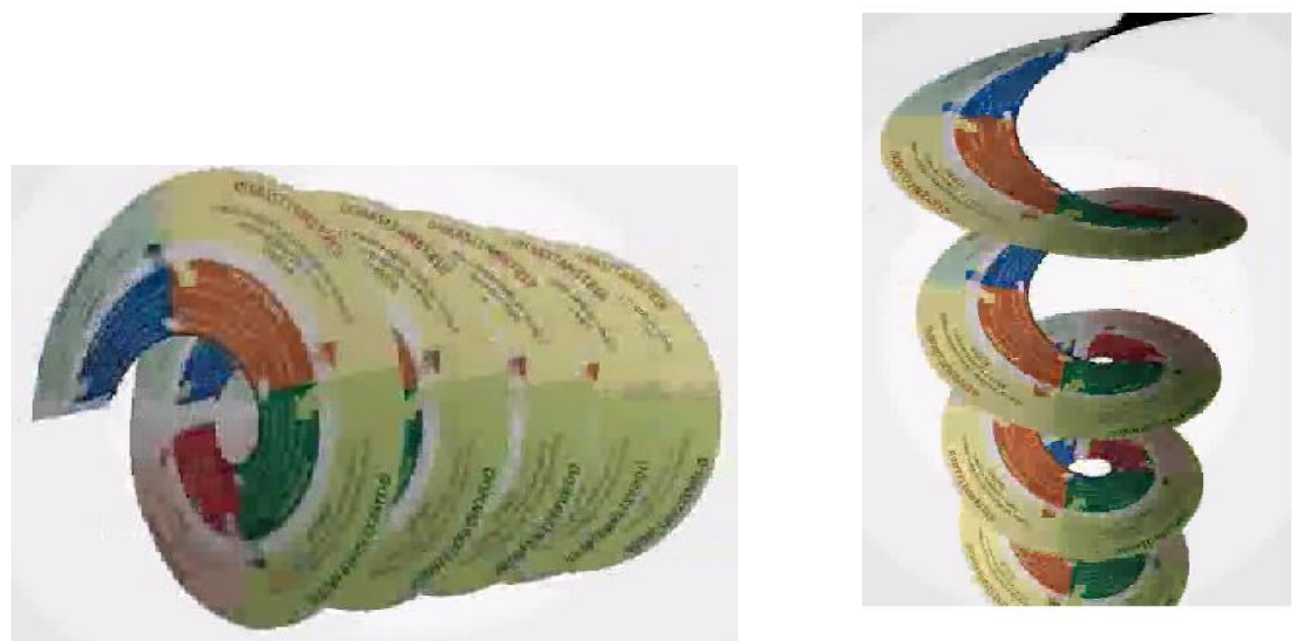

Dados: Elaboração própria (ARNONI, no prelo)

AGRADECIMENTOS: Ao Conselho Nacional de Desenvolvimento Científico e Tecnológico $(\mathrm{CNPq})$, pelo financiamento da pesquisa (Universal - Processo: 484970/2013-5).

\section{REFERÊNCIAS}

ARNONI, M. E. B. Didática e mediação pedagógica: da Universidade à Escola Básica. Currículos, sistemas de avaliação e práticas avaliativas: da Escola Básica à Universidade. Granville M.A. (org.) Campinas, SP, 2011. p.191-218.

ARNONI, M. E. B. Metodologia da Mediação Dialética na organização da atividade educativa: Educação em Ciências. In: Metodologias e processos formativos em 
ciências e matemática. GOIS J. (Org.). Paco Editorial: Jundiai. 2014. ISBN: 978-858148-649-9. p.99-119.

ARNONI, M. E. B. Teoria pedagógica da Metodologia da Mediação Dialética: uma abordagem ontológica do processo educativo. In: PERINELLI NETO, H. (Org.). Ensino e teorias: diálogos com a epistemologia e a ontologia. Porto Alegre: Editora FI, no prelo.

BOORSTIN, J. The Hollywood Eye: what makes movies work. New York: Cornelia \& Michael Bessie Books, 1990.

BORBA, M. C.; SCUCUGLIA, R. R. S.; GADANIDIS, G. Fases das tecnologias digitais em educação matemática: sala de aula e internet em movimento. 1. ed. Belo Horizonte: Autêntica, 2014.

BRUNER, J. S. The culture of education. Cambridge, MA: Harvard University Press, 1996.

GADANIDIS, G.; BORBA, M. C. Our lives as performance mathematicians. For the Learning of Mathematics, v. 28, n. 1, p. 44-51, 2008.

LUKÁCS, G. Ontologia do Ser Social: os princípios ontológicos fundamentais de Marx. São Paulo: Livraria Editora Ciências Humanas, 1979.

MARX, K. Manuscritos Econômico-filosóficos. [1844] Tradução de Jesus Ranieri. $1^{\text {a }}$ reimp. São Paulo, SP: Boitempo, 2006.

SCUCUGLIA, R. R. S. On the nature of students' digital mathematical performances: when elementary school students produce mathematical multimodal artistic narratives. 1. ed. Saarbrucken, Deutschland: Verlag / Publisher: LAP LAMBERT Academic Publishing, 2012.

SCUCUGLIA, R. R. S. Narrativas multimodais: a imagem dos matemáticos em performances matemáticas digitais. Bolema - Boletim de Educação Matemática (in press), v. 28, n. 49, p. 950-973, 2014.

STAKE, R. Case Studies. Handbook of qualitative research. $2^{\mathrm{a}}$ ed. Thousand Oaks, CA: Sage Publications, 2000, p. 435-454.

TONET, I. Um novo horizonte para a educação. In: I Congresso de Ontologia do Ser e Educação, IBILCE-UNESP- São José do Rio Preto, nov/dez 2007.

WALSH, M. Multimodal Literacy: researching classroom practice. Australia: Primary English Teaching Association (e:lit), 2011. 


\section{Como referenciar este artigo}

ARNONI, M. E. B.; SCUCUGLIA, R A produção de vídeos na formação inicial de professores em Didática da Matemática. Revista on line de Política e Gestão Educacional, Araraquara, v.21, n.esp.3, p. 1575-1587, dez., 2017. ISSN: 1519-9029.

Submetido em: 03/07/2017

Aprovado em: 08/08/2017 